\title{
Doctors, medical societies and the pharmaceutical industry
}

$\mathrm{O}$ ur second annual meeting to be held in conjunction with the American College of Chest Physicians (ACCP) is rapidly approaching. Last November we held a successful initial joint meeting in Philadelphia, Pennsylvania. The Canadian Thoracic Society (CTS) focused on traditional respiratory topics, such as exercise, sleep, asthma and acute respiratory distress syndrome. The ACCP educational agenda was broader, and was driven to some degree by the tragic deaths of September 11th. They included topics on bioterrorism and anthrax. This year we will continue to focus on clinical topics relevant to Canadian pulmonary physicians. As well, we are very pleased to announce that DrE Phillipson has agreed to give the Christie Memorial Lecture this year.

The CTS executive, staff and board have invested a great deal of effort to try to make this year's meeting successful. One crucial element for success is the support of Canadian pharmaceutical companies. Meetings are expensive propositions today. If all the costs of these meetings were to be borne by the attendees, the costs would be prohibitive. In addition, pharmaceutical financial support allows society meetings to generate additional revenues that can then be used to support the daily running of the society. Finally, pharmaceutical companies can offer their expertise in marketing and arranging additional meetings to help make society meetings successful. We are relying on Canadian companies to support us in all of the aspects of our annual general meeting. With this in mind, it is an opportune time for all of us to review our relationship with the Canadian pharmaceutical industry.

It is clear that pharmaceutical companies invest heavily in physicians. A position paper by the American College of Physicians and the American Society of Internal Medicine has recently addressed some of the issues that both physicians and pharmaceutical companies face (1). In 1999, the United States pharmaceutical industry spent nearly US\$8.0 billion to send sales representatives to physicians' offices and to exhibit their products at conferences. Because these companies have a financial obligation to their shareholders, they must feel that this is money well spent to further their interests. However, both physicians and industry have their own internal codes and guidelines to help maintain an ethical relationship with each other. It is possible for both physicians and industry to benefit while still upholding the guiding principles of beneficence (acting in a patient's best interests), nonmaleficence (protecting the patient from harm), autonomy (having respect

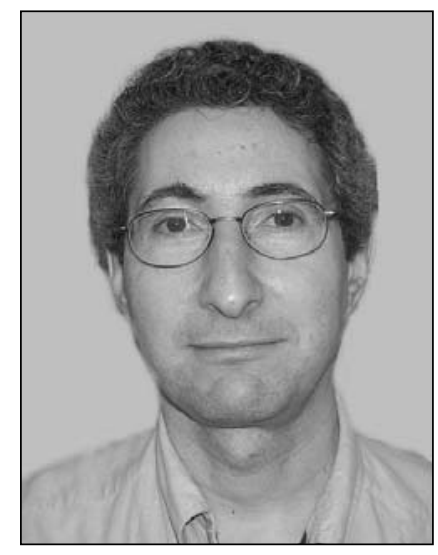

Irvin Mayers for the patient and fostering informed choice) and, finally, justice (promoting equity in health care). However, there must be clear guidelines to reduce even perceived conflict of interest. The CTS is in the process of finalizing guidelines to reduce conflicts and yet still try to obtain benefit for our society, and ultimately for the patients who we see. There is an expectation that CTS board members will not use their positions on committees to receive direct benefits from industry and that they will not use confidential information to seek financial gain. Our policy statements do not explicitly address our society's interactions with industry. We are, however, aware that industry-sponsored educational events may have biases toward the sponsor's products. We are obligated to present balanced views and to present the best available evidence in all our educational endeavours, even if it is at odds with the sponsor's interests. We are obligated to define clearly potential conflicts of interest in order for our educational events to meet Royal College of Physicians and Surgeons MAINCERT certification. As well, we must live up to the spirit intended by conflict of interest guidelines and not just live up to the letter of the law.

Industry research and support is a major source of advancement in medical science, and its desire to disseminate this information fills an important educational need. We can all benefit from this interaction, but as a profession- 
al society and as individual practitioners, we must always be careful to not overstep the boundaries surrounding conflict of interest. The American College of Physicians and American Society of Internal Medicine guidelines explicitly address these interactions between medical societies and industry (2). In all our interactions, we should always be aware that a conflict of interest may develop. A quick rule of thumb to guide personal interactions with industry is: "Are you willing to tell your colleagues and your patients what you are doing?" If the answer is "no", you have probably over stepped the boundary. For a medical society, this rule of thumb can be extended to include telling our membership what we are doing on their behalf.

I believe that our meeting, although supported extensively by industry, is free of conflict of interest. We have received unrestricted educational grants for our planned events. We are soliciting industry to help offset some travel costs for individual society members. We are also asking industry to sponsor its own independent events to increase attendance at the CTS annual meeting. We hope that our annual general meeting will be a success but not at the expense of our society's intellectual independence.

Irvin Mayers MD FRCPC

President, Canadian Thoracic Society

\section{REFERENCES}

1. Coyle SL. Physician-industry relations. Part 1: Individual physicians. Ann Intern Med 2002;136:396-402.

2. Coyle SL. Physician-industry relations. Part 2: Organizational issues. Ann Intern Med 2002;136:403-6. 


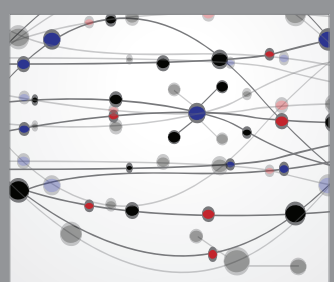

The Scientific World Journal
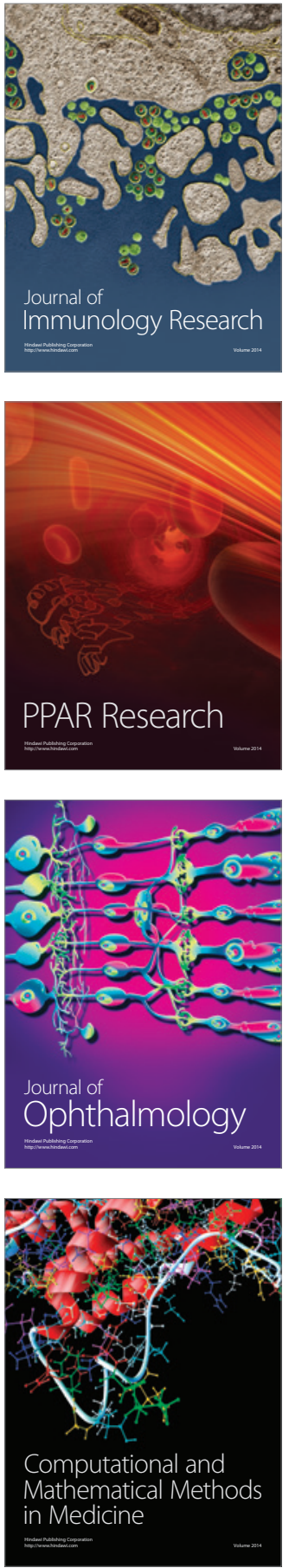

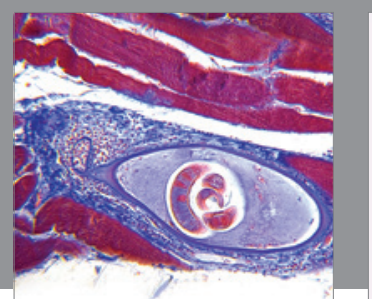

Gastroenterology Research and Practice

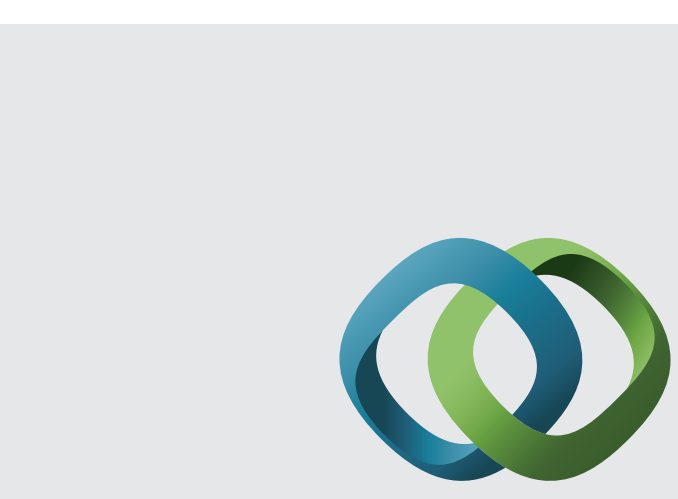

\section{Hindawi}

Submit your manuscripts at

http://www.hindawi.com
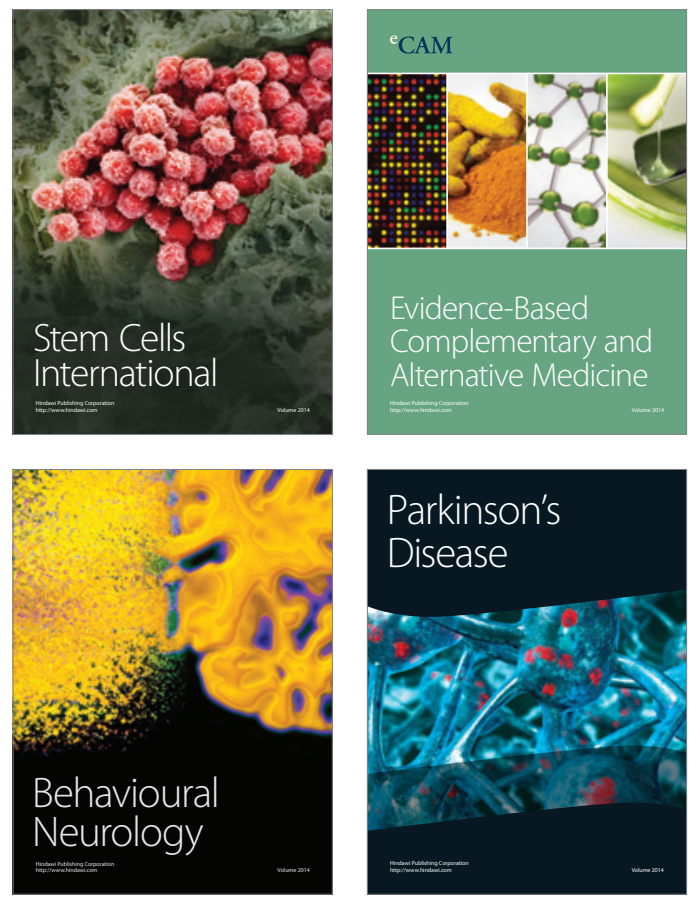
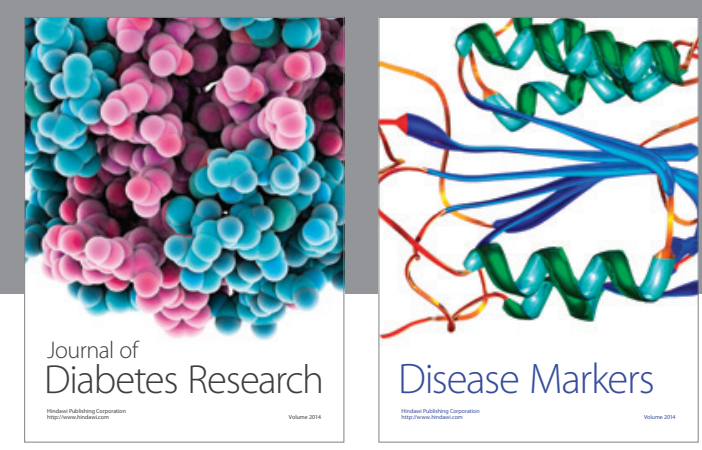

Disease Markers
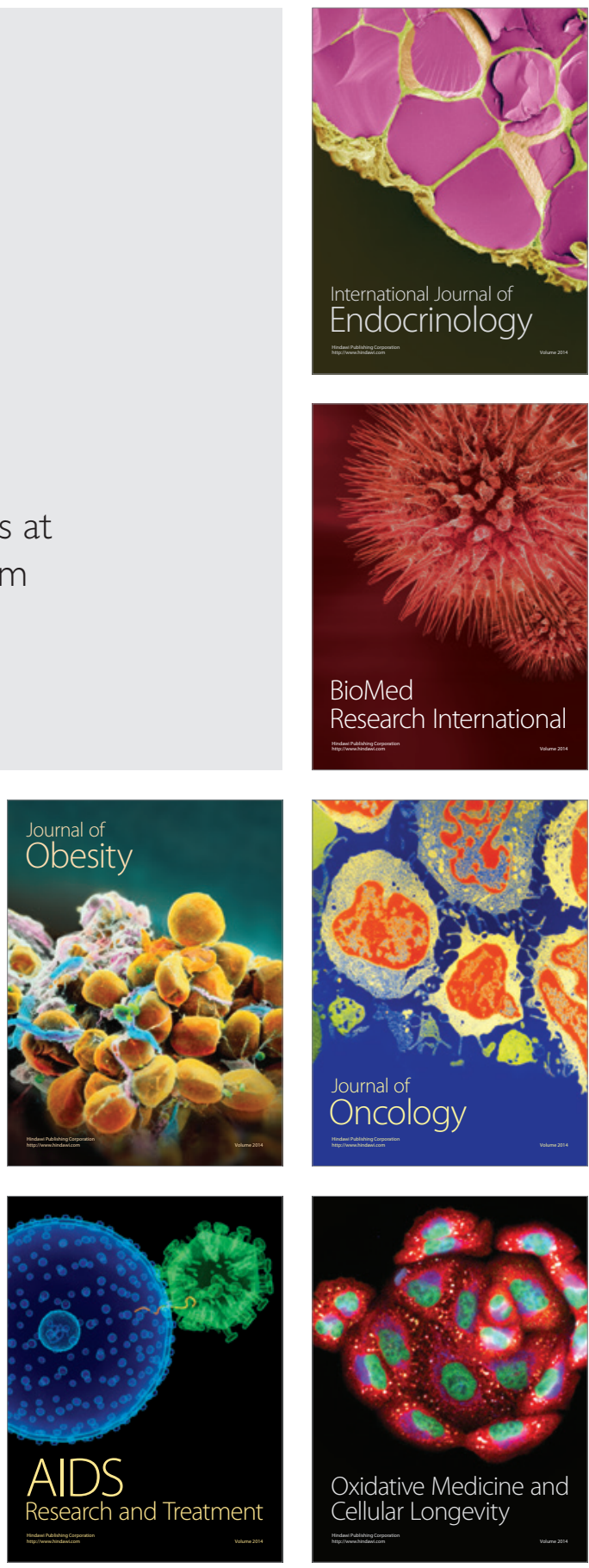